\title{
Práticas colaborativas \& bioética: a interdisciplinaridade do conflito
}

\author{
Collaborative practices \& bioethics: the interdisciplinarity of conflict
}

\author{
Jamile Garcia De Lucca \\ Universidade do Extremo Sul Catarinense (PPGD/UNESC) \\ Mestra em Direitos Humanos e Sociedade \\ Criciúma / Santa Catarina / Brasil \\ jamilegdelucca@gmail.com \\ Maria de Fátima Schumacher Wolkmer \\ Universidade do Extremo Sul Catarinense (PPGD/UNESC) \\ Doutora em Direito pela Universidade Federal de Santa Catarina- UFSC \\ Professora no Programa de Pós-Graduação em Direito da UNESC \\ Criciúma / Santa Catarina / Brasil \\ mfwolkmer@yahoo.com.br \\ Gustavo Silveira Borges \\ Universidade do Extremo Sul Catarinense (PPGD/UNESC) \\ Doutor em Direito pela Universidade Federal do Rio Grande do Sul - UFRGS \\ Professor e Pesquisador do Programa de Pós-Graduação em Direito na UNESC. \\ Criciúma / Santa Catarina / Brasil \\ gustavoborges@hotmail.com
}

Resumo: Diante dos avanços materiais e tecnológicos da medicina, a expectativa de vida aumentou significativamente. No entanto, em que pese a redução de doenças e mortalidades, quando o paciente se encontra acometido por doenças incuráveis ou não mais responsivas a tratamentos, surgem os conflitos de fim de vida. A contemporaneidade nos coloca diante de novos tipos de conflitos, tão complexos que ultrapassam as concepções tradicionais de Direito ou Medicina. Levando isso em consideração, o presente artigo busca explicitar como as Práticas Colaborativas podem auxiliar na transição dos conflitos de fim de vida a partir de um diálogo interdisciplinar, considerando a Bioética e seus princípios. O método de abordagem utilizado é o dedutivo, com técnica de pesquisa bibliográfica e procedimento monográfico.

Palavras-chave: conflito de fim de vida; bioética; comitês de bioética; práticas colaborativas.

Abstract: Due to material and technological advances in medicine, life expectancy has increased significantly. However, despite the reduction in disease and mortality, when the patient is affected by incurable diseases or those no longer responsive to treatments, end-of-life conflicts arise. Contemporaneity presents us with new types of conflicts, so common that they go beyond traditional conceptions of Law or Medicine. Taking this into account, this article seeks to explain how Collaborative Practices can help in the transition from end-of-life conflicts through an interdisciplinary dialogue, considering Bioethics and its principles. The method of approach used was the deductive, with bibliographic research and monographic procedure.

Keywords: end-of-life conflict; bioethics; bioethics committees; collaborative practices.

\section{Para citar este artigo}

ABNT NBR 6023:2018

DE LUCCA, Jamile Garcia; WOLKMER, Maria de Fátima Schumacher. Práticas colaborativas \& bioética: a interdisciplinaridade do conflito. Prisma Jurídico, São Paulo, v. 20, n. 1, p. 116-134, jan./jun. 2021. http://doi.org/10.5585/prismaj.v20n1.16793. 


\section{Introdução}

Em face dos progressos científicos, a sociedade, como também os operadores de direito e medicina, depara-se imersos em um processo de mudanças muito abrangente, de forma que a consequência disso é o aumento expressivo de conflitos. Aspirando evitar os excessos dos avanços tecnológicos, como a manutenção da vida a qualquer custo, a Bioética surge com o compromisso de equilíbrio e preservação dos seres humanos, perfazendo o estudo das dimensões morais, materiais e subjetivas que envolvem a vida e a morte, analisando controvérsias de maneira interdisciplinar.

Na mesma linha interdisciplinar de transição de conflitos, as Práticas Colaborativas método que capacita as partes por meio dos advogados colaborativos, assim como, quando necessário, de profissional de finanças colaborativo, de profissional da saúde mental colaborativo, dentre outros profissionais neutros -, utilizam o saber de várias disciplinas por meio da colaboração para que os envolvidos se tornem protagonistas e coautores de acordos equilibrados, respeitosos e duradouros.

Ante a tais conjecturas, com o presente artigo pretende-se questionar o seguinte: como, historicamente, surgiu a Bioética, seus Comitês e as Práticas Colaborativas? Como as Práticas Colaborativas e os Comitês de Bioética manejam os conflitos sob a ótica da interdisciplinaridade? Há a possibilidade de os conflitos de fim de vida serem transformados com a adoção das Práticas Colaborativas?

Nessa direção, busca-se desenhar algumas respostas a essas questões, propondo um exame do tema a partir da compreensão conceitual e histórica da Bioética, dos Comitês de Bioéticas e das Práticas Colaborativas. Na sequência, discorrer-se-á sobre o conflito e o conflito bioético, relacionando-os com a interdisciplinaridade integrante dos Comitês de Bioética e das Práticas Colaborativas, que podem solucioná-los. Por fim, objetiva-se demonstrar a viabilidade do emprego das Práticas Colaborativas como um processo na transformação de conflitos de fim de vida. Para tanto, será utilizado o método dedutivo, aplicando-se as técnicas de pesquisa bibliográfica e documental.

\section{Bioética, comitês de bioética e práticas colaborativas: aspectos históricos e conceituais}

As ponderações sobre Bioética não são novas. Desde os gregos e romanos já existia uma preocupação ética e filosófica acerca da medicina; porém, enquanto disciplina, a Bioética, historicamente, surgiu a partir de uma sucessão de acontecimentos, como explica Ramos (2009), entre os quais o julgamento do Tribunal de Nuremberg, em 1947, quando vinte médicos 
nazistas e três administradores médicos foram acusados de assassinatos, torturas e outras atrocidades cometidos em nome da ciência médica. Tal veredito afirmou que as evidências haviam demonstrado a prática, durante a Segunda Grande Guerra, de experimentos médicos em cidadãos não alemães, tanto prisioneiros de guerra quanto civis, incluindo judeus e apátridas (heimatlos), os quais foram realizados em larga escala na Alemanha e nos países por ela ocupados.

O referido Tribunal reconheceu que estes tipos de experiências médicas não estavam em conformidade com a ética da profissão e delineou dez princípios básicos que deveriam ser observados para satisfazer as exigências morais, éticas e legais. Estes princípios se tornaram conhecidos como o Código de Nuremberg (JONSEN, 2000).

A descoberta do Ácido Desoxirribonucleico (DNA), por James Watson, em 1953, também foi um importante fator na ampliação do campo da Bioética com as temáticas da genética e da hereditariedade, chegando aos limites de um interesse político na (re)produção humana, conhecida como limpeza racial, para combater a "eugenia negativa". De acordo com esta visão, seria possível discernir a existência de qualidades boas e ruins nos indivíduos conforme sua genética, com o propósito de selecionar as "melhores pessoas" para criar uma raça superior. Os eugenistas negativos trabalhavam classificando os traços humanos para melhorar o estoque nacional (Alemanha Nazista) ao promulgarem programas legais de esterilização e restrição imigratória, dando ensejo ao ressurgimento de visões xenofóbicas (JONSEN, 2000).

Outros grandes experimentos com seres humanos também contribuíram para a formação da Bioética. Pode-se fazer referência ao caso Willowbrook State School, ocorrido em uma escola para crianças com deficiência cognitiva na qual foram realizados experimentos para verificar a eficácia da profilaxia contra hepatite, infectando, de maneira proposital, aproximadamente 700 (setecentas) crianças com as cepas do vírus, na ocasião, sendo seus pais coagidos a consentirem. Outro caso célebre aconteceu no hospital Jewish Chronic Disease, no qual foram injetadas células cancerígenas em 22 (vinte e dois) pacientes com idades já avançadas, sem seus consentimentos. Destaca-se, também, o chamado Tuskegee Syphilis Study, realizado com o auxílio de 600 (seiscentos) homens negros que foram infectados com sífilis, os quais participaram da experimentação com o objetivo de determinar os efeitos do curso natural da doença não tratada, ficando pelo menos 399 desses portadores da enfermidade sem receber tratamento ou informações acerca do estágio de sua enfermidade (RAMOS, 2009).

A seleção de pacientes para hemodiálise crônica, em Seattle, no ano de 1962, culminou em inúmeras discussões éticas quando John Mayers, que se encontrava no último estágio de 
uma doença renal crônica, submeteu-se a esse tipo de tratamento. Dispondo de um único aparelho para tanto, foi organizado um comitê - formado por uma dona de casa, um bancário, um advogado, um pastor, um funcionário do Estado, um cirurgião e um sindicalista - para deliberar quais pacientes deveriam ser submetidos ou não a essa intervenção (RAMOS, 2009).

Referido Comitê elaborou uma lista de considerações que julgavam relevantes: idade, sexo, estado civil e número de dependentes, renda, escolaridade, ocupação, desempenho passado e potencial futuro. Usando esses critérios simplistas - que passaram a ser designados como critérios de valor social -, foi escolhido quem deveria viver e quem deveria morrer (JONSEN, 2000), originando o primeiro Comitê de Ética da Medicina.

Sobre o assunto, citam Goldim e Francisconi (1995):

[...] O Dr. Wilhelm Kolff, inventor do dialisador, questionou se "devemos aceitar o princípio de que a posição social deva determinar a seleção dos pacientes”? Devemos permitir diálise apenas em pacientes casados, que vão à igreja, tem filhos, tem emprego, bom salário e colaborem com ações comunitárias?

Com o advento da modernidade, promoveram-se inúmeros avanços no campo da saúde, entre os quais o reconhecimento de novos fármacos e de cirurgias que prolongam a vida do ser humano; entretanto, alguns desses avanços oscilaram entre a vida e a dizimação humana (RAMOS, 2009). Principalmente após os horrores causados na Segunda Grande Guerra, urgiu a necessidade de serem repensados os limites das ações humanas no campo da medicina e de preservação da dignidade da pessoa humana, dando origem à Bioética (DINIZ, 2002).

Os estudos de Hoss (2013, p. 84) demonstram que o pioneiro a utilizar a palavra Bioética (bio + ethik) foi o alemão teólogo protestante Fritz Jahr, o qual caracterizou a palavra como o reconhecimento de obrigações éticas, não apenas em referência ao ser humano, mas em um sentido amplo, englobando todos os seres vivos. Para Jahr, a compaixão é algo intrínseco do ser humano e, na sua visão, a Bioética consiste no "respeito diante da vida".

Nesse contexto, Hoss (2013) explica que Van Renssealer Potter, oncologista norteamericano, introduziu o pluralismo moral, asseverando que a Bioética é a resposta à crise tecnológica e, de acordo com Sgreccia (2009), também introduziu a abordagem interdisciplinar da Bioética, com o intuito de incluir ponderações não somente da medicina, como também de outras áreas.

Em sentido amplo, a Bioética se afigura como 
[...] uma resposta da ética às novas situações oriundas da ciência no âmbito da saúde, ocupando-se não só dos problemas éticos, provocados pelas tecnociências biomédicas e alusivos ao início e fim da vida humana, às pesquisas em seres humanos, às formas de eutanásia, à distanásia, às técnicas de engenharia genética, aos métodos de reprodução humana assistida, à eugenia, à eleição do sexo futuro descendente a ser concebido, à clonagem de seres humanos, à maternidade substitutiva, à escolha do tempo para nascer ou morrer, à mudança de sexo em caso de transexualidade, à esterilização compulsória de deficientes físicos ou mentais, à utilização da tecnologia do DNA recombinante, às práticas laborais de manipulação de agentes patogênicos etc., como também decorrentes da degradação do meio ambiente, da destruição do equilíbrio ecológico e do uso de armas químicas (DINIZ, 2002, p. 10-11).

A Bioética pode ser definida, segundo a Grande Enciclopédia Larousse Cultural (1998), como "[...] o conjunto dos problemas colocados pela responsabilidade moral dos médicos e biólogos em suas pesquisas teóricas ou nas aplicações práticas dessas pesquisas”, não podendo ser concebida como um simples confronto de opiniões, mas uma procura de respostas adequadas que está presente necessariamente na interdisciplinaridade (SGRECCIA, 2009).

Com a Bioética, deu-se impulso à criação do que hoje chama-se de Comitês de Bioética, considerados

\begin{abstract}
Espaços em que se podem encontrar num contexto pluralista, e com uma metodologia interdisciplinar, os diversos componentes dos vários setores das atividades conexas com a vida e a saúde do homem, sejam eles vários setores das atividades conexas com a vida e a saúde do homem, sejam eles locais de hospitalização, instituições clínicas de pesquisa ou laboratórios de pura experimentação. Nesses espaços, os membros adequadamente preparados serão chamados a enfrentar os diversos problemas éticos que aos poucos se evidenciam, procurando chegar a uma solução operacional o mais coerente possível com os valores e princípios fundamentais que o comitê terá esclarecido e declarado no próprio estatuto [...] (SGRECCIA, 2009, p. 244-245).
\end{abstract}

No Brasil, os Comitês de Bioética Hospitalar têm os quatro princípios propostos por Beauchamp e Childress (1999), quais sejam, o respeito à autonomia, da não maleficência, da beneficência e da justiça, como sendo o norte das escolhas éticas.

O princípio do respeito à autonomia considera que o indivíduo possui o direito de se autodeterminar, no sentido de ter suas opiniões, eleger suas escolhas e agir com base em valores e crenças pessoais; implica em assegurar as condições necessárias para que ele faça as suas escolhas com autonomia. O princípio da não maleficência, por sua vez, consiste em não infligir dano intencionalmente; diante de um conflito ético, prevalece esse princípio ao da beneficência. O princípio da beneficência se baseia em prevenir o dano e o mal, devendo-se evitar ou recusar o dano e o mal e procurar fazer o bem (BEAUCHAMP; CHILDRESS, 1999).

Ainda, como pedra angular, há o princípio da justiça, o qual se consubstancia em caráter de justiça social. Ante as diversas misérias que assolam o mundo e o Brasil, principalmente, imperioso ter um olhar mais aguçado para compreender as várias realidades existentes que 
impedem algumas pessoas de ter o mesmo tratamento - ou entendimento de que tenham direito - no tocante à distribuição dos recursos destinados ao financiamento da assistência à saúde, de modo a proporcionar um mínimo digno de atendimento e suprimento da carência ao acesso desses serviços (BEAUCHAMP; CHILDRESS, 1999).

Assim como os Comitês de Bioética têm a característica interdisciplinar na busca da resolução de conflitos, também a possuem as Práticas Colaborativas.

De acordo com os estudos de Schwab (2004), em 1990, Stuart Webb, advogado praticante de direito de família, compreendendo que não se tratavam de questões meramente legais, mas sim de relacionamentos pessoais com vínculos legais, passou a procurar uma maneira de melhor resolver os conflitos de divórcio para todos os membros da família. Rejeitando o caráter litigante, Webb começou a experimentar com outros advogados um processo colaborativo com as partes.

Para tanto, cessou com os processos litigiosos e só representou clientes que optaram por participar ativamente das negociações para alcançar um acordo benéfico a todos. Com esse propósito, em carta endereçada ao Juiz Sandy Keith, do estado norte-americano de Minnesota, delineou sua crença no por que um acordo qualificado faria a diferença. Em particular, ele observou que os advogados colaborativos serão motivados a desenvolver habilidades de negociação no modelo ganha-ganha, como as praticadas em mediação, defendendo que, sob esse novo sistema, os advogados seriam liberados para usar suas verdadeiras competências, ou seja, análise, resolução de problemas, criação de alternativas, planejamento imobiliário e olhando para o quadro geral sobre o que é justo (SCHWAB, 2004).

Nos raros casos em que o processo de negociação não foi alcançado, explica Schwab (2004, p. 355), Webb se retirou, e o cliente foi obrigado a encontrar novos procuradores para então continuar com o litígio, dando início ao que hoje chamamos de Direito Colaborativo. O experimento de Webb se transformou em um movimento, constituindo o Collaborative Law Institute, uma organização sem fins lucrativos que ajuda a difundir a doutrina do direito colaborativo.

A psicóloga Peggy Thompson e a advogada Pauline H. Tesler (2017) também merecem destaque neste artigo, uma vez que foram responsáveis por inovar o Direito Colaborativo, ampliando a ideia original de Stuart, incluindo uma equipe interdisciplinar, a qual passou a contar com profissionais da saúde mental (psicólogos, psiquiatras ou assistentes sociais) e finanças, além de profissionais neutros de outras áreas, dando, assim, origem à chamada Collaborative Practices ou Práticas Colaborativas. 
As Práticas Colaborativas podem ser conceituadas como método colaborativo não adversarial e interdisciplinar que auxilia na transição de conflitos, contando com uma equipe formada por dois advogados colaborativos, profissional de finanças colaborativo (contador/administrador), profissional da saúde mental colaborativo (psicólogo, psiquiatra ou assistente social), entre outros profissionais neutros.

Ao se concentrar na construção conjunta em prol de um acordo entre as partes, tal prática é pautada em auxiliá-las para que sejam protagonistas e corresponsáveis. Quando não existe negociação, os envolvidos, que já assinaram a cláusula de não litigância, necessariamente, devem procurar outros advogados para representá-los em Juízo, bem como outros profissionais, o que aumenta a probabilidade de fechamento da avença. Esse modelo é mais frequentemente usado na área do direito de família, todavia pode ser aplicado a qualquer área em que as pessoas desejem alcançar uma solução mutuamente benéfica e evitar litígios.

\section{A interdisciplinaridade como construção de respostas aos conflitos}

O ser humano é sociável, razão pela qual os conflitos de naturezas diversas existem. Muitos deles estão enraizados na essência do homem e nas suas culturas. Os conflitos são um estado natural da existência humana e mesmo que desagradáveis, nunca irão desaparecer, visto que os seres humanos são capazes de raciocinar, possuem gostos e desgostos específicos, ou seja, onde houver pessoas com objetivos diferentes, haverá um conflito em potencial.

A partir das luzes lançadas, é natural que ora se questione o que é conflito. Seria um sinônimo de combate? Poderia significar oposição, divergência ou diferentes interesses, pois são muitos os significados que automaticamente se associam à acepção de conflito. No entanto, essa associação revela a percepção do conflito como algo somente negativo, induzindo à crença de que ele deva ser, sempre que possível, evitado. Mas, na verdade, essa percepção negativa não traduz esse fenômeno em sua integralidade, já que não se pode olvidar de sua função social de modificações culturais e evoluções de realidades não praticadas anteriormente ante a atual conjectura da modernidade.

Como sublinhado por Moore (1995, p. 5), todas “[...] as sociedades, comunidades, organizações e relacionamentos interpessoais experimentam conflitos em um ou outro momento no processo diário de interação. O conflito não é necessariamente ruim, anormal ou disfuncional, é um fato da vida".

Quando se infere que o conflito pode ter efeito positivo, é justamente porque as mudanças se dão pela insuficiência e pela ineficácia dos modelos que outrora eram vigentes. 
Ao se analisar a história da humanidade, consegue-se observar momentos de continuidades e rupturas. Novos rumos da história são modificados e transformados por diversos fatores exemplos disso são as crises, as revoluções, as guerras, os quais mudam amplamente as conjunturas da sociedade.

Com o desenvolvimento dos povos e o aprimoramento cultural, atrelados ao reconhecido progresso científico da Medicina e a outros avanços, tais como a vacinação, a quimioterapia e o uso de antibióticos, corroborou-se o prolongamento da sobrevida do ser humano, dando origem a novos conflitos, quais sejam, os conflitos bioéticos.

Os dilemas bioéticos estão relacionados a questões morais, éticas e emocionais, envolvendo juízos de valor que culminam em julgamentos baseados em pontos de vista pessoais sobre o "mais aceitável" ou a "melhor solução disponível nas circunstâncias reais para aquele caso" - este último compreendido pela bioética complexa, defendida por Morrein (1986).

Os conflitos bioéticos se enquadram entre todas as consequências e decisões que podem ser tomadas acerca da vida e da morte do ser humano, tais como o aborto, a experimentação com o homem, o transplante de órgãos, a eutanásia, a ortotanásia, a distanásia, a transfusão de sangue e a esterilização humana artificial. Exsurge, ainda, a preocupação relacionada à macrobiótica e à preservação do meio ambiente ecologicamente equilibrado, isso com o desígnio de perpetuar a vida humana.

No presente artigo, foram considerados, especialmente, os conflitos bioéticos de fim da vida, que envolvem pacientes acometidos por enfermidades cuja patogenia não seja mais responsiva à cura, pacientes com Câncer terminal, Esclerose Lateral Amiotrófica (ELA), Alzheimer, Parkinson, dentre outras doenças decorrentes da senilidade.

A depender do avanço do estágio da saúde, chega-se a um momento em que não se pode mais fazer intervenções propriamente ditas com o objetivo de conter a doença ou de fazê-la regredir, de modo que nessa situação toda intervenção terapêutica corre o risco de ser desproporcional (SGRECCIA, 2009). Em consequência, o processo de luto tem início antes mesmo de a morte acontecer. Quando a enfermidade aparece, doenças crônicas e avançadas, que não respondem mais ao tratamento curativo, desencadeiam, também, processos de perdas progressivas, inexistindo a possibilidade de cura. Desse modo, a energia pode ser investida em cuidar e dar qualidade à vida que resta para que viva até o fim (ASTUDILLO et al., 2007).

Quanto mais se avança na ciência e na medicina, mais se prolonga a sobrevida, ao mesmo tempo que teme-se a morte, também a nega-se. Mesmo assim, o doente em estágio terminal que se recusar a receber tratamento médico ou quiser interrompê-lo a fim de morrer de uma forma que, de acordo com as suas convicções e crenças pessoais, parece-lhe ser a mais 
digna, exerce o seu direito de autonomia, o qual é reconhecido pela Constituição brasileira (MOLLER, 2007).

No entanto, o paciente com enfermidade avançada, muitas vezes, é tratado como alguém sem direito a opinar; assim, na maioria dos casos, um familiar ou outra pessoa é quem tomará as decisões por ele. Quando este indivíduo é hospitalizado, pouco a pouco corre o risco de ser tratado com um objeto, ou seja, de ser desumanizado, pois se tem o intuito de prolongar, a qualquer custo, a vida desse ente querido (KÜBLER-ROSS, 1996).

Nesse sentido, disserta Kübler-Ross (1996, p. 20-21):

Se tenta reagir, logo lhe dão um sedativo e, depois de horas de espera e conjecturas sobre suas forças, é conduzido para a sala cirúrgica ou para unidade de terapia intensiva, transformando-se num objeto de grande preocupação. [...] Pode clamar por repouso, paz e dignidade, mas recebe em troca infusões, transfusões, coração artificial, ou uma traqueotomia, se necessário. Pode desejar que alguém pare por um instante para fazer só uma pergunta, mas o que vê é uma dúzia de pessoas olhando um relógio, todas muito preocupadas com as batidas de seu coração, com seu pulso, com o eletrocardiograma, com o funcionamento dos pulmões, com as secreções ou excreções, mas não com o ser humano que há nele.

Por outro lado, também é comum a literacia em saúde, ou seja, a inabilidade do paciente de compreender as informações repassadas e de usá-las para tomar decisões conscientes sobre a sua enfermidade e os cuidados médicos. Há também enfermos em estágios terminais que optam por tomar decisões em conjunto com os familiares e amigos. Por fim, surgem aqueles que desejam conferir as deliberações bioéticas a um terceiro neutro.

Os conflitos decorrentes do fim da vida, embora sejam de grande complexidade, podem ser conduzidos adequadamente, compreendendo esse processo e, ao mesmo tempo, incentivando o desenvolvimento de medidas colaborativas para a família e as pessoas próximas, perfazendo uma resolução que considere todos os seus multifatores.

Os Comitês de Bioética, hoje, estão sendo postos como órgãos de suporte para decisões referentes aos protocolos de experimentação e situações que possam se apresentar com caráter inovador ou de valor ético incerto. Ou seja, dá-se a passagem da função de órgãos de emergência à função de apoio e de ponto de referência constante (SGRECCIA, 2009).

Sabe-se que a Medicina não é uma ciência simples, mas um conjunto de ciências. Ao mesmo tempo que é das ciências “experimentais", é das ciências "humanas", isso porque o forte cunho unitário que o humano imprime - seu conjunto de conexões com o ambiente, suas energias físicas, psíquicas e espirituais - transcende a unidade fenomenológica (SGRECCIA, 2009, p. 248-249). 
Assim, os Comitês de Bioética são grupos interdisciplinares que deliberam analisando pormenorizadamente todas as circunstâncias da situação concreta e identificando possíveis soluções razoáveis, fazendo-se necessária a pluralidade na inclusão de profissionais de outras áreas, como do direito, assistentes sociais, psicólogos, antropólogos, líderes religiosos, médicos de áreas diversas. O intuito é o de abranger todos os distintos "olhares" que a sociedade possui acerca de um dilema bioético (LOCH; GAUER; CASADO, 2008, p. 227-228).

A tomada de decisão dos Comitês de Bioéticas se dá, outrossim, pelo conhecimento de todos os parâmetros que contribuem para a definição das responsabilidades do médico em relação ao doente, considerando as leis civis e penais do Estado (SGRECCIA, 2009).

Em especial, a antropologia tem um aspecto peculiar nas respostas aos conflitos bioéticos ante as novas tecnologias e a organização social da medicina e do direito, na medida em que concebe a percepção do valor deontológico da vida, de suas prerrogativas e de suas tarefas, excluindo as demais formas de instrumentalização, a transcendência da pessoa e a concepção integral de pessoa - valores físicos, psicológicos e espirituais (SGRECCIA, 2009). Não é possível tratar a doença como algo que acontece apenas com o corpo, mas com a pessoa como um todo.

A interdisciplinaridade se refere à transferência de saberes de uma disciplina a outra quando vários conhecimentos se juntam formando um fio condutor resolutivo para determinado conflito. Cada profissional não pode enfrentar certos obstáculos por si só, então utiliza conhecimentos advindos de outros profissionais, promovendo-se o exercício da interdisciplinaridade - porque eles interagem entre si. É um efetivo processo intrapessoal que facilita a resolução adequada ao conflito, o qual não poderia ser atingido se somente profissionais individuais estivessem atuando separadamente.

A importância do pensar a partir da complexidade humana, reintegrando as formas do saber, é o que Edgar Morin (1998) consubstancia no paradigma da complexidade. Nesse influxo, 
[...] o pensamento complexo tenta ter em linha de conta aquilo de que se desembaraçam, excluindo, os tipos mutiladores de pensamento a que chamo simplificadores e, portanto, ela luta não contra o incompleto, mas sim contra a mutilação. Assim, por exemplo, se tentarmos pensar o fato de que somos seres simultaneamente físicos, biológicos, sociais, culturais, psíquicos e espirituais, é evidente que a complexidade reside no fato de se tentar conceber a articulação, a identidade e a diferença entre todos estes aspectos, enquanto o pensamento simplificador ou separa estes diferentes aspectos ou os unifica através de uma redução mutiladora. Portanto, nesse sentido, é evidente que a ambição da complexidade é relatar articulações que são destruídas pelos cortes entre disciplinas, entre categorias cognitivas e entre tipos de conhecimento. De fato, a aspiração à complexidade tende para o conhecimento multidimensional. Não se trata de dar todas as informações sobre um fenômeno estudado, mas de respeitar as suas diversas dimensões; assim, como acabo de dizer, não devemos esquecer que o homem é um ser bio-sociocultural e que os fenômenos sociais são, simultaneamente, econômicos, culturais, psicológicos etc. (MORIN, 1998, p. 138).

Seguindo tal concepção, não se pode limitar as soluções para os dilemas bioéticos à normatividade, tampouco se pode balizar somente no paradigma cartesiano do cuidado da saúde, enxergando o corpo como um objeto; a conotação sobre o que é o certo ou o justo pode mudar conforme a religião, a cultura, os valores intrínsecos, etc. (BORGES, 2017).

Assim, utilizando-se da contribuição de diversos saberes - geralmente profissionais do direito, da assistência social, da antropologia, da teologia, médicos de diversas especializações, pessoa civil neutra, dentre muitos outros -, em conjunto, logra-se encontrar justificações/soluções éticas para dilemas éticos.

Do mesmo modo, as Práticas Colaborativas buscam transformar os conflitos com o auxílio da equipe interdisciplinar para a construção de acordos duradouros, visto que “[...] lidar com cada componente de conflito requer que os envolvidos na resolução do conflito tenham diferentes habilidades" (CAMERON, 2019, p. 31).

Citando-se a situação específica que ensejou as Práticas Colaborativas, a decisão do divórcio implica frustração, medo, perda de referências, de projetos, de patrimônios, de tempo com os filhos, solidão, raiva e muita angústia. Em tal contexto, o bom acordo é o que planeja o futuro, é a oportunidade de refletir sobre o que a pessoa quer conservar e aquilo que já não quer mais ter: "eu tenho um futuro pela frente", "que vida você vai viver agora?", "não é o fim da vida, só daquele casamento" (POPPE, 2017, p. 67).

$\mathrm{O}$ ajuste bem-sucedido ocorre na medida em que os indivíduos experimentam poucos sintomas relacionados ao divórcio, são capazes de funcionar bem em novos papéis familiares, profissionais ou escolares, e desenvolvem uma identidade e um estilo de vida que não estão mais ligados ao casamento (POPPE, 2017). Consequentemente, os primeiros efeitos negativos do divórcio em adultos podem ocorrer anos antes da separação final e da dissolução legal. Além disso, o conflito evidente entre pais durante esse período pode levar a problemas 
comportamentais em crianças - que podem ser vistos como efeitos iniciais da dissolução conjugal (DAVIES; CUMMINGS, 1994).

Em tal cenário, destaca-se o modelo mais comum de equipe colaborativa em um processo colaborativo, qual seja: dois advogados colaborativos, o profissional da saúde mental colaborativo para o casal e para o infanto-juvenil e um neutro financeiro.

Representando cada cliente, os advogados colaborativos, possuindo formação em mediação, "[...] atuam como educadores e guias ao longo de todo o processo de colaboração e acordo" (WEBB; OUSKY, 2017, p. 96). Com base no "tripé de sustentação" - total transparência, retirada da equipe e não litigância - incentivam os clientes a se engajarem na resolução conjunta do problema, respeitando a ética com a transparência entre os envolvidos, limitando os seus serviços com a cláusula de "não litigância" (WEBB; OUSKY, 2017, p. 96).

O profissional de saúde mental colaborativo (psicólogo e/ou psiquiatra) auxilia na nova reorganização da vida, focando especificamente nos problemas emocionais decorrentes do divórcio, contribuindo para a preservação do vínculo com os filhos.

O profissional de finanças colaborativo assessora as partes na organização e na análise das informações financeiras, oferecendo conhecimento para que elas possam se reeducar financeiramente. Já o profissional da saúde mental colaborativo especialista em criança/adolescente (psicólogo e/ou pedagogo) atua em separado com os filhos, de forma focada, visando a resultados em curto prazo, nutrindo suas necessidades em primeiro plano e primando para que seja um processo o menos traumático possível.

O modelo de equipe exige que cada profissional colaborativo tenha noção da área de especialidade dos outros profissionais, além de dominar a sua própria. No entanto, não deve ultrapassar o seu limite profissional para que assim a interdisciplinaridade funcione (CAMERON, 2019).

Nancy Cameron (2019, p. 34) discorre acerca da importância da equipe interdisciplinar no processo colaborativo:

\footnotetext{
A equipe oferece proteção ao casal enquanto ele passa pela transição do divórcio. [...] A equipe de divórcio é estruturada contratualmente, permitindo que todos os membros da equipe se comuniquem sobre as partes e as questões com as quais estão trabalhando [...] a natureza não adversarial do processo colaborativo se estende a todos os membros da equipe e ninguém (nem mesmo os coaches, o especialista neutro financeiro ou o especialista neutro infanto-juvenil) vai ao tribunal caso esse processo fracasse.
}

Nessa direção, são realizadas várias reuniões visando compor o acordo, pois o divórcio colaborativo é uma negociação estruturada que prossegue em estágios. Segundo Cameron (2019), como em uma gestação, existem três fases típicas de um divórcio colaborativo: 
concepção, gestação e nascimento. A concepção "vai do primeiro contato com o cliente até a primeira reunião a quatro e a assinatura do contrato de participação"; a gestação dar-se-á pelas reuniões a quatro e todo o trabalho intermediário; o nascimento, por sua vez, "é a fase em que seguem caminhos separados em uma família reestruturada, cortando o cordão umbilical” (CAMERON, 2019, p. 179-181). Essas reuniões podem se prolongar tempo suficiente para que as partes estejam convictas de suas decisões para que, assim, possam se tornar protagonistas de seus acordos.

\section{Práticas colaborativas como meio adequado de transformação de conflito bioético de fim de vida}

A proposta do presente artigo, então, é apresentar as Práticas Colaborativas como possível ferramenta a ser utilizada para a resolução de conflitos éticos de fim de vida. A morte, segundo Astudillo et al. (2007, p. 27, grifo nosso),

[...] es parte de la vida y todos tarde o temprano nos enfrentamos a ella. La muerte nos lleva a la convicción, viendo en ella un valor pedagógico, de que todos somos transeúntes en esta tierra, por lo que es preciso vivir plenamente el presente como una referencia de nuestra mortalidad, recordando que no disponemos de un tiempo ilimitado. El momento actual es esencial para que se realice lo que da significado y la emoción al vivir, intensidad al amor y a cualquier sentimiento. Es más conveniente considerar que sin la muerte, el presente no tendría valor y aprender a vivir cada día como si fuera el único que tenemos para sacarle mayor provecho.

Quando há doenças crônicas, avançadas e progressivas, que já não respondem ao tratamento, pode-se investir a energia em cuidar e dar qualidade de vida ao paciente. Deve-se mudar a ideia de que não há nada a fazer nessa fase e que isso é apenas uma espera angustiante antes da morte, considerando esse momento como uma última oportunidade para a aproximação, a resolução, o cuidado mútuo e uma reunião. Alguns pacientes e algumas famílias decidem ir para a morte por um caminho "menos difícil" (ASTUDILLO et al., 2007, p. 12), de modo consciente e positivo, olhando diretamente para a situação. É essencial que os profissionais tenham a oportunidade de acompanhar as pessoas que vivem essas situações, transmitindo afeição e segurança para ajudá-las a resolver as questões pendentes (ASTUDILLO et al., 2007).

A lenta progressão da doença também permite a incorporação da morte à vida, faz com que se fale sobre ela nesse momento e que seja reconhecida como um fenômeno natural em que é possível intervir com resultados muito positivos para a força da família. Todas as famílias mudam com uma pessoa doente. A atenção a pequenos detalhes e trabalhar para obter uma 
morte em paz podem transformar positivamente a experiência e a memória em relação a esses parentes (ASTUDILLO et al., 2007).

Ao utilizar as Práticas Colaborativas, pode-se chegar a um consenso sobre quais caminhos serão percorridos até o fim da vida, por meio do desenvolvimento de um processo colaborativo em que são realizadas reuniões com profissionais da saúde mental, profissional financeiro colaborativo e outros profissionais neutros, com um advogado colaborativo representando o enfermo e sua família e outro representando o hospital.

Devido ao grau de emoções que envolvem o luto e a aceitação da morte, sugere-se o auxílio espiritual no processo colaborativo. Como bem observa Goldim, Salgueiro e Raymundo (2007), no processo de tomada de decisões sobre o fim da vida, os aspectos religiosos ou espirituais estavam presentes, mesmo que não evidentes, sendo o termo espiritualidade definido como:

[...] uma dimensão distintiva, potencialmente criativa e universal da experiência humana, surgindo tanto dentro da experiência subjetiva interna dos indivíduos como dentro das comunidades, grupos e tradições. Pode ser experimentado como um relacionamento com aquilo que é intimamente "interior", imanente e pessoal dentro do eu e dos outros, e/ou como um relacionamento com aquilo que é totalmente "outro", transcendente e além do eu. É experienciada como sendo de importância fundamental ou definitiva e, portanto, preocupada com significado e propósito na vida, verdade e valores (WATTIS; CURRAN; ROGERS, 2017, p. 4, tradução nossa).

Para muitas pessoas, a espiritualidade não é somente a que envolve uma fé em Deus e/ou uma fé religiosa organizada, ela está relaciona a uma busca para dentro, de dentro para fora, um sentido de algo que transcende ao mundo material. Como dispôs Gilbert (2013, p. 27): "como seres em forma de porquê, estamos em uma jornada contínua de descobertas".

John Swinton e Stephen Pattison (2010, p. 226-237, tradução nossa) elencam algumas características centrais da espiritualidade, como a) significado: o significado ontológico da vida; fazer sentido de situações da vida; derivando o propósito de existência; b) valor: crenças e padrões que são valorizados; ter a ver com a verdade, a beleza, o valor de um pensamento, objeto ou comportamento; frequentemente discutidos como "valores finais"; c) transcendência: experiência e valorização de uma dimensão além do eu; expansão de limites próprios; d) Conectando: relacionamentos com o eu, outros, Deus/poder superior e o meio ambiente; e) Tornar-se: um desdobramento da vida que exige reflexão e experiência; inclui uma noção de quem é e como se sabe.

Assim, tendo a espiritualidade como complemento intrínseco ao rol de possibilidades na transformação de conflitos de fim de vida, forma-se o modelo de práticas colaborativas.

Na Figura 1, abaixo, segue demonstrada a formação de uma equipe colaborativa: 
Figura 1 - Formação de uma equipe colaborativa

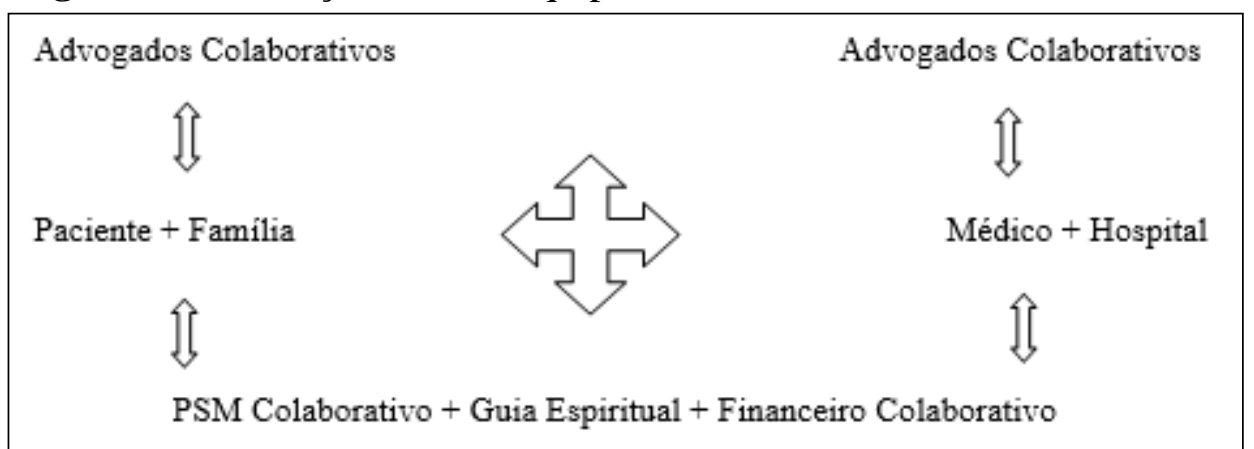

Fonte: Elaboração própria (2021).

O processo colaborativo pode ser iniciado com a figura dos advogados colaborativos, sendo cada envolvido assessorado por um advogado, que os conduzirá ao diálogo colaborativo, proporcionando um espaço sem julgamento ou preconceito, de modo a alcançar uma transição que funcione, com o mesmo objetivo de ajudar o paciente, sua família e o hospital a projetar caminhos que sejam aceitos por todos (CAMERON, 2019).

Advogados colaborativos diferenciam-se do advogado tradicional litigante, pois permitem que os envolvidos estejam focados no diálogo consensual, sem que a ameaça de tornar a situação litigiosa (ir ao judiciário) esteja à espreita a qualquer momento. Assim, os advogados colaborativos "reúnem recursos e ferramentas típicas do mediador com a essência da advocacia" (FÜRST, 2016), ajudando os participantes com o rapport, a escuta ativa e as perguntas para identificarem seus verdadeiros e próprios interesses, construindo opções que serão mais úteis e benéficas.

O Profissional da Saúde Mental Colaborativo tem um papel fundamental nesse processo, pois contribui muito para o entendimento do processo de luto do paciente, da família e dos demais envolvidos. Uma pessoa, no final de sua vida, e todos que com ela se relacionam apresentam numerosos e intensos sintomas que causam um grande impacto emocional. Então, o objetivo de quem intervém nessa fase é ajudá-los a viver o presente da melhor forma possível para atenuar os efeitos da sua doença, os sintomas, a ansiedade, os medos e as frustrações, conforme sua história, como também preparar para a vida posterior à morte (ASTUDILLO et al., 2007).

Como explicam Goldim, Salgueiro e Raymundo (2007, p. 25), “o diálogo respeitoso sobre as convicções religiosas dos envolvidos e as implicações das práticas propostas quase sempre é suficiente para encontrar alternativas que respeitem as restrições de consciência de ambas as partes".

O cuidado espiritual e, quando apropriado, uma estrutura religiosa, serão vitais especialmente no momento da despedida. Isso não é apenas para a pessoa que está enfrentando 
a morte, mas para os cuidadores familiares e os amigos, como também para os funcionários do hospital que se importam (GILBERT, 2013).

O Profissional de Finanças Colaborativo também é imprescindível ao se ter um diagnóstico terminal, pois esse profissional irá organizar as finanças pessoais e familiares, programando, em conjunto, o quanto pode ser gasto em remédios e com as despesas do hospital ao longo do tempo, auxiliando em uma construção conjunta de um plano financeiro de fim de vida.

Após os trabalhos dos profissionais de saúde mental colaborativos e do finanças colaborativo, dá-se a escritura de declaração prévia da vontade do paciente terminal ou do testamento vital elaborada/o juntamente com os advogados colaborativos, podendo ser definida/o como

[...] um documento escrito por uma pessoa capaz, no pleno exercício de suas capacidades, com a finalidade de manifestar previamente sua vontade, acerca dos tratamentos e não tratamentos a que deseja ser submetido quando estiver impossibilitado de manifestar sua vontade, diante de uma situação de terminalidade (DADALTO, 2020, p. 110).

Sobre seus benefícios, Dadalto (2020, p. 112) afirma que:

[...] o benefício das diretivas antecipadas quanto ao melhoramento da relação médicopaciente, à autoestima do paciente e à diminuição de sentimento de culpa e indecisão dos parentes é induvidoso. Não se pode ainda fechar os olhos para o caráter econômico da questão, uma vez que a autonomia decisória do paciente impacta diretamente na sustentabilidade do sistema de saúde, seja ele público ou privado.

Assim, o paciente terá a possibilidade de "consentir e assumir consequências previsíveis do tratamento médico que lhe será aplicado" (LUX, 2011, p. 376, tradução nossa). Após passado todo o processo colaborativo, estando o paciente consciente do seu querer, a família já poderá estar um pouco mais preparada e/ou ter aceitado que o fim da vida estará próximo. O que se deve levar em conta é que as Práticas Colaborativas podem levar um tempo, sendo praticadas até que o paciente se sinta confortável em falar e tomar decisões de fim de vida, podendo ser realizado acordos provisórios, moldando-se a cada caso.

Por derradeiro, vale destacar o seguinte trecho de Milan (2016, p. 140-141), em seu romance "A Mãe Eterna: morrer é um direito", que narra a história da relação entre uma mãe quase centenária e sua filha, que se vê na condição de ser mãe da própria mãe durante seus momentos de fim de vida: 
Falei, me lembrando do seu ensinamento. Tratar o corpo do morto é uma prática antiquíssima. Todas as grandes civilizações... Foi você que me introduziu na tanatopraxia. Tudo será feito como se deve. Até porque eu me deixo orientar por você, que está e vai ficar comigo. Quem ama não se separa. O meu luto começou no dia em que eu quis que você nascesse de mim como eu de você... quis insensatamente te dar a vida. Acreditava que podia curar suas mãos já inteiramente tomadas pela doença. Naquele dia, te perdi por ter desejado ser a mãe da mãe. Como Asclépio, neguei a realidade, imaginando que podia ressuscitar os mortos. Não sabia ainda que, sem que eu fizesse esforço, você renasceria no meu coração e nós continuaríamos juntas. [...] vai entrar no túmulo da família ao som de um silêncio grandioso - o dos que nunca renunciaram à independência.

\section{Considerações finais}

O presente trabalho procurou demonstrar o uso das Práticas Colaborativas como resolução adequada de conflitos éticos de fim de vida, sendo uma possível alternativa disponível ao paciente, a seus familiares e ao hospital.

Assim, com este estudo, conclui-se que a Bioética teve uma grande importância em relação aos avanços da medicina nos cuidados e pesquisas com humanos, principalmente com a criação dos Comitês de Bioética, da mesma maneira que as Práticas Colaborativas surgiram para aprimorar as resoluções de conflitos.

Logo, o processo colaborativo é um experimento valioso na transformação de conflitos, o qual deve ser endossado levando-se em consideração o aspecto multifatorial dos conflitos de fim de vida com uma resposta interdisciplinar. Dessa maneira, o paciente e seus familiares poderão vivenciar menos sofrimento e dor, tornando o desejo do doente uma experiência "melhor ou menos pior" no final de sua vida.

É essencial que a vontade, o sofrimento e as crenças das pessoas sejam ouvidas, respeitadas e transformadas. Desse modo, tais ações serão suficientes para resilir os conflitos bioéticos de fim de vida, auxiliando os envolvidos no processo de luto e trazendo-os à consciência. Para tanto, é imprescindível que as partes, dentro do processo colaborativo, se tornem protagonistas.

Com o auxílio da equipe colaborativa, que trabalhará interdisciplinarmente, possibilitase o suporte necessário para a elaboração da escritura de declaração prévia de vontade do paciente terminal, pois com o amparo psicológico, médico e jurídico para tanto, honram-se a autonomia do paciente, a sua integridade pessoal e familiar, sobretudo para a aceitação da morte. 


\section{Referências}

ASTUDILlO, Wilson A.; PÉREZ, Magdalena; ISPIZUA, Ángel; ORBEGOZO, Ana. Acompañamiento en el duelo y medicina paliativa. San Sebastián: Sociedad Vasca de Cuidados Paliativos, 2007.

BEAUCHAMP, Tom L.; CHILDRESS, James F. The Principles of biomedical ethics. New York: Oxford, 1999.

BORGES, Gustavo, Bioética aplicada e aspectos jurídicos da prática hospitalar. $1^{\text {a }}$ ed. São Paulo: Multideia, 2017.

CAMERON, Nancy. Práticas Colaborativas: aprofundando o diálogo. São Paulo: Instituto Brasileiro de Práticas Colaborativas, 2019.

DADALTO, Luciana. Testamento Vital. 5. ed. Rio de Janeiro: Lumen Juris, 2020.

DAVIES, Patrick T.; CUMMINGS, Mark. Marital conflict and child adjustment: an emotional security hypothesis. Psychological Bulletin, v. 116, n. 3, p. 387-411, nov. 1994. Disponível em: https://doi.org/10.1037/0033-2909.116.3.387. Acesso em: 27 abr. 2021.

DINIZ, Maria Helena. O estado atual do biodireito. 2. ed. Aum. e atual. São Paulo: Saraiva, 2002.

FÜRST, Olivia. Práticas Colaborativas: novos paradigmas do Direito. [S.1., s.n.], 2016. Disponível em: https://eadb8bd0-05e9-4321-820894abdc89bf26.filesusr.com/ugd/e910af_eeb0834e7bb74ecfa29d05b5828cff18.pdf. Acesso em: 27 abr. 2021.

GILBERT, Peter. Spirituality and End of Life Care. Brighton: Pavilion Publishing and Media Ltd., 2013.

GOLDIM, José Roberto; SALGUEIRO, Jennifer Braathen; RAYMUNDO, Márcia Mocellin. Bioética \& Espiritualidade. Porto Alegre: EDIPUCRS, 2007.

GOLDIM, José Roberto; FRANCISCONI, Carlos Fernando. Os comitês de ética hospitalar. Revista de Medicina ATM, Porto Alegre, v. 15, n. 1, p. 327-334, 1995. Disponível em: https://www.ufrgs.br/bioetica/comitatm.htm. Acesso em: 27 abr. 2021.

GRANDE Enciclopédia Larousse Cultural. São Paulo: Nova Cultural, 1998.

HOSS, Geni Maria. Fritz Jahr e o Imperativo Bioético: debate sobre o início da Bioética na Alemanha e sua importância em nível internacional. Revista Bioethikos, São Camilo/SP, v. 7, n. 1, p. 84-86, jan./mar. 2013. Disponível em: https://saocamilosp.br/assets/artigo/bioethikos/99/a10.pdf. Acesso em: 27 abr. 2021.

JONSEN, Albert R. A short history of medical ethics. New York: Oxford University Press, 2000 . 
KÜBLER-ROSS, Elizabete. Sobre a morte e o morrer. Rio de Janeiro: Martins Fontes, 1996.

LOCH, Jussara de Azambuja; GAUER, Gabriel José Chittó; CASADO, María

(Org.). Bioética, interdisciplinaridade e prática clínica. Porto Alegre: EDIPUCRS, 2008.

LUX, Laura Mayer. Autonomía del paciente y responsabilidade penal médica. Revista de Derecho, Valparaíso, n. 37, p. 371-413, 2011. Disponível em:

https://scielo.conicyt.cl/pdf/rdpucv/n37/a09.pdf. Acesso em: 27 abr. 2021.

MILAN, Betty. A mãe eterna: morrer é um direito. Rio de Janeiro: Record, 2016.

MOLLER, Letícia L. Direito à morte com dignidade e autonomia. Curitiba: Juruá, 2007.

MOORE, Christopher W. O processo de mediação: estratégias práticas para a resolução de conflitos. 2. ed. Porto Alegre: Artmed, 1995.

MORIN, Edgar. Ciência com Consciência. 2. ed. Rio de Janeiro: Berhand, 1998.

MORREIN, E. Haavi. Philosophy lessons from the clinical setting: seven sayings that used to annoy me. Theoretical Medicine and Bioethics, Switzerland, v. 7, p. 47-63, 1986.

Disponível em: https://doi.org/10.1007/BF00489423. Acesso em: 27 abr. 2021.

POPPE, Diane. Manual do bom divórcio: para ler antes de se separar (ou de se casar). São Paulo: Principium, 2017.

RAMOS, Dalton Luiz de Paula. Bioética: pessoa e vida. Caetano do Sul: Difusão, 2009.

SCHWAB, William H. Collaborative Lawyering: A Closer Look at an Emerging Practice.

Pepperdine Dispute Resolution Law Journal, Malibu, v. 4, n. 3, jan. 2004. Disponível em: https://digitalcommons.pepperdine.edu/drlj/vol4/iss3/4/. Acesso em: 27 abr. 2021.

SGRECCIA, Elio. Manual de Bioética: fundamentos e ética biomédica. 3. ed. São Paulo: Loyola, 2009. V. 1.

SWINTON, John; PATTISON, Stephen. Moving beyond clarity: towards a thin, vague and useful understanding of spirituality in nursing care. Nursing Philosophy, [S.1.], v. 11, n. 4, p. 226-37, out. 2010. Disponível em: https://doi.org/10.1111/j.1466-769X.2010.00450.x. Acesso em: 27 abr. 2021.

THOMPSON, Peggy; TESLER, Pauline H. Divórcio Colaborativo: a maneira revolucionária de reestruturar sua família, resolver problemas legais e seguir adiante. São Paulo: Instituto Brasileiro de Práticas Colaborativas, 2017.

WATTIS, John; CURRAN, Stephen; ROGERS, Melaine. Spiritually Competent Practice in Health Care. Boca Raton: CRC Press, 2017.

WEBB, Stuart G.; OUSKY, Ronald D. O caminho colaborativo para o Divórcio: método revolucionário que, sem recorrer ao tribunal, resulta em menos estresse, custos menores e crianças mais felizes. São Paulo: Instituto Brasileiro de Práticas Colaborativas, 2017. 